OPEN ACCESS

Edited by:

Johan Korhonen,

Åbo Akademi University, Finland

Reviewed by:

Lars Orbach

Federal University of Minas Gerais,

Brazil

Orly Rubinsten,

University of Haifa, Israel

*Correspondence:

Ann Dowker

ann.dowker@psy.ox.ac.uk

Specialty section:

This article was submitted to Educational Psychology, a section of the journal

Frontiers in Psychology

Received: 14 November 2021 Accepted: 24 January 2022

Published: 07 March 2022

Citation:

Dowker A and Sheridan H (2022) Relationships Between Mathematics

Performance and Attitude to Mathematics: Influences of Gender, Test Anxiety, and Working Memory.

Front. Psychol. 13:814992.

doi: 10.3389/fpsyg.2022.814992

\section{Relationships Between Mathematics Performance and Attitude to Mathematics: Influences of Gender, Test Anxiety, and Working Memory}

\author{
Ann Dowker ${ }^{1 *}$ and Hannah Sheridan ${ }^{2}$ \\ ${ }^{1}$ Department of Experimental Psychology, University of Oxford, Oxford, United Kingdom, ${ }^{2}$ Lady Margaret Hall, University of \\ Oxford, Oxford, United Kingdom
}

Many studies have indicated that mathematics anxiety, and other negative attitudes and emotions toward mathematics, are pervasive and are associated with lower mathematical performance. Some previous research has suggested that working memory is related to both mathematics anxiety and mathematics. Moreover, both gender and chosen course of study (sciences vs. humanities) appeared likely to influence students' attitudes to mathematics. In the present study, 40 university undergraduates completed a battery of assessments investigating working memory, attitude to mathematics, test anxiety. and mental and written arithmetic. Attitudes to mathematics were significantly associated with the other variables: working memory, test anxiety, and both measures of mathematical performance. The other variables were not strongly associated with one another. There were no gender differences in mathematical performance, but females exhibited more negative attitudes to mathematics and higher test anxiety than males. After controlling for test anxiety, there ceased to be significant gender differences in attitudes to mathematics. Science students had more positive attitudes to mathematics than humanities students, but the groups did not differ in test anxiety, Science students were better at written but not mental arithmetic. They were also better at working memory, but this was not a significant covariate when the groups were compared on mathematical performance and attitudes to mathematics The results are discussed, with particular focus on implications for future research on influences on mathematics anxiety.

Keywords: mathematical performance, attitudes to mathematics, test anxiety, working memory, gender differences, adults

\section{INTRODUCTION}

Numerous studies indicate that attitudes to mathematics are often highly negative, ranging from boredom to severe fear and anxiety. Mathematics anxiety has been defined as "feelings of tension or anxiety that interfere with the manipulating of numbers or the solving of mathematical problems" (Richardson and Suinn, 1972). Estimates of the frequency of 
mathematics anxiety range from $11 \%$ (Betz, 1978) to $68 \%$ (Richardson and Suinn, 1972). The frequency of mathematics anxiety will depend both on the nature of the sample and on how "mathematics anxiety" is defined, but even the lower estimates suggest that it is significant problem for many. Moreover, even people who do not have mathematics anxiety as such may have negative attitudes to mathematics and regard it as boring, a waste of time, too difficult for them, and/or irrelevant to their own lives (see Fennema and Sherman, 1976).

Many studies have also found that mathematics anxiety and other negative attitudes to mathematics are associated correlationally, with poorer performance in mathematics (e.g., Hembree, 1990; Ma and Kishor, 1997; Maloney et al., 2011; Carey et al., 2016; Dowker et al., 2016; Zhang et al., 2019; Abín et al., 2020).

This does not mean that the direction of causation is always from anxiety or negative attitudes to performance. Weaknesses in mathematics may cause failures and other negative experiences, which then lead to anxiety and other negative attitudes (NúñezPeña and Suárez-Pellicioni, 2014). It is generally thought now that there is a bidirectional relationship between attitudes and performance. For example, Maloney and Beilock (2012) propose that a combination of social factors and pre-existing mathematical difficulties results a negative attitude to mathematics. This in turn impedes subsequent performance in mathematics, resulting in a vicious circle.

This study also investigates; the possible relationship between attitude to mathematics and working memory. There are some studies that suggest that mathematics anxiety may impair performance by overloading working memory (Eysenck and Calvo, 1992; Ashcraft and Kirk, 2001). Beilock and DeCaro (2007) found that, in studies of mathematics anxiety, there was only a correlation between mathematics anxiety and mathematics performance when the task given required significant use of working memory resources. Ashcraft and Kirk (2001) supported this idea by finding that people with higher mathematics anxiety demonstrated lower working memory than people with less mathematics anxiety, particularly in tasks involving calculation. Caviola et al. (2012) suggested, similarly, that if anxiety affects working memory, it should have an especially strong effect on arithmetic, as mathematics requires working memory. Vukovic et al. (2013) drew together these ideas and showed that, in a longitudinal study of 113 children, the relationship between mathematics anxiety and performance is greater in those with poorer working memory abilities. This study will examine the relationships between working memory, mathematics anxiety, and mathematical performance in adults.

Some apparent "mathematics anxiety" may in fact reflect a less specific anxiety about academic subjects and especially about tests and examinations. There is usually found to be a high correlation between mathematics anxiety and test anxiety, with typical correlations ranging from 0.3 to 0.5 (Hembree, 1990; Ashcraft et al., 1998). However, mathematics anxiety is not just a form of test anxiety, studies generally show a higher correlation between different measures of mathematics anxiety $(0.5-0.8)$ than between mathematics anxiety and test anxiety or general anxiety (Dew et al., 1983; Hembree, 1990; Ashcraft and Ridley, 2005).

A number of studies have attempted to investigate and disentangle the interrelationships between mathematics performance, mathematics anxiety, working memory, and sometimes other characteristics. These studies have given interesting but sometimes somewhat conflicting results. For example, structural equation modeling has been used to obtain a finer-grained analysis of the relationships between mathematical performance, mathematics anxiety, working memory, and other cognitive skills, sometimes producing somewhat contrasting results. Skagerlund et al. (2019) used structural equation modeling to analyze the interrelationships between mathematics anxiety, mathematical performance, and working memory. They found three separate pathways from mathematics anxiety to mathematical performance: a direct effect of mathematics anxiety on performance; an indirect effect via effects on symbolic number processing; and an indirect effect via effects on working memory. Douglas and Lefevre (2018) also used structural equation modeling to investigate the interrelationships between the above variables and the mathematics-related skills of quantity processing and spatial processing. Although all these variables were correlated, no direct link was found between mathematics anxiety and either quantity processing, spatial processing or working memory; nor were the relationships between the latter abilities and mathematics performance indirectly affected by working memory.

Meta-analyses have been used to combine the results of numerous studies in order to obtain more precise and detailed information about the relationships between mathematics anxiety and mathematical performance and factors that may contribute to such relationships. Zhang et al. (2019) and Barroso et al. (2021) carried out meta-analyses, both of which showed a moderate consistent negative correlation between mathematics anxiety and mathematical performance. The relationship was strongest in secondary school pupils and lowest in children in grades 3 to 5 and in college students. Zhang et al. (2019) also examined the effects of other demographic and methodological variables and found that the relationship between mathematics anxiety and performance was stronger for Asian than European students and was strongest among studies that used a custom test and studies that assessed problem-solving skills. A meta-analysis by Caviola et al. (2021) indicated that both mathematics anxiety and test anxiety were negatively associated with mathematical performance. Working memory had a weak moderating effect on these relationships. Namkung et al. (2019) carried out a meta-analysis specifically of studies of school age pupils and found that the relationship between mathematics anxiety and performance was strongest when the mathematics anxiety measures included both affective and cognitive components; when the mathematics performance measures involved formal assessments that influenced or reflected school grades; and when the mathematics performance measures involved advanced and/or multi-step arithmetic.

One consistent finding from most previous studies is that there are significant gender differences in attitudes to mathematics. Most studies indicate that females show higher 
mathematics anxiety than males (e.g., Hembree, 1990; Miller and Bichsel, 2004; Devine et al., 2012; Ganley and Vasilyeva, 2014; Sarfo et al., 2020; Wang, 2020; Xie et al., 2020; Delage et al., 2021). Some studies have shown such gender differences even in children in the early years of primary school (Szczygiel, 2020), though many studies have not found such a difference (e.g., Harari et al., 2013; Ching, 2017; Mononen et al., 2021). Most of the studies (with a few exceptions) do not show gender differences in mathematical performance. Spelke (2005) reported that in countries where girls have equal education and opportunities, there is no significant gender difference in mathematics performance. Some studies suggest that mathematics anxiety has different effects on performance in males and in females, but the studies give conflicting results as to the direction of the gender difference. Hembree (1990) and Miller and Bichsel (2004) found that mathematics anxiety affected performance more in males than in females. Devine et al. (2012) found on the other hand that after controlling for test anxiety, mathematics anxiety had an independent effect on mathematics performance in girls but not in boys. Hembree (1990) drew attention to the lack of conclusive agreement across studies, as to relationship between gender, mathematics anxiety, and mathematical performance, which Birgin et al. (2010) later attributed to the lack of consistent measurement of mathematics anxiety. The current study, therefore, intends to further investigate the influence of gender on mathematics performance and on a measure related to mathematics anxiety while controlling for test anxiety.

The current study also intends to investigate the relationship between attitude to mathematics and degree subject of study. Betz (1978) found that correlations between mathematics anxiety and performance in university students differed according to course as well as gender. Ashcraft (2002) suggested that correlations between mathematics anxiety and performance could be because those that have higher levels of mathematics anxiety avoid situations involving mathematics, which may mean avoiding certain areas of study, and, thus, gain less practice in mathematics. Thus, the current study intends to investigate how gender and subject of study interact with any relationships between mathematics performance and mathematics anxiety. We tentatively propose that science students may have higher working memory than humanities students, because their area of study may require more short-term mental mathematical and logical calculations, as compared with analyses of long-term information. Popescu et al. (2019), found that mathematics graduate students scored higher on backward digit span and on another working memory task (forward letter span) than humanities graduate students.

The current study investigates relationships between all these variables; attitudes to mathematics, mathematics performance, gender, degree subject, and working memory. The participants in the study were Oxford University students and therefore could be assumed to exclude those with extremely poor mathematical performance (entry requirements usually include a high grade in mathematics at GCSE or equivalent). Therefore, it was decided to use a mathematics attitude measure that did not focus solely on negative attitudes, but included both enjoyment and anxiety. The measure chosen was Aiken's (1974) Mathematics Enjoyment Scale. This also had the advantage of not being very time-consuming, though this also comes with the disadvantage of not being able to include several different factors. Because many of the questions are in fact about anxiety, the construct measured will be termed Mathematics Enjoyment/ Anxiety.

Given previous findings about the complicated relationships between mathematics anxiety, test anxiety, and mathematics performances anxiety, mathematics performance (e.g., Devine et al., 2012), a standard measure of test anxiety was also included. The measures of mathematics performance were chosen because they both included only topics that are covered in compulsory school mathematics courses. Thus, it is unlikely that the specific content learnt in the degree would be an additional factor influencing mathematics performance. The decision to use a numerical working memory test seemed most appropriate to the field of mathematics anxiety as this tests working memory for numbers, which is required in mathematics.

Our predictions were (1) that mathematics performance would correlate with both attitudes to mathematics and working memory; (2) that both mathematics anxiety and working memory would be independent predictors of mathematics performance in a multiple regression; (3) that general test anxiety would correlate with both mathematics performance and attitudes to mathematics; (4) that mathematics performance measures and test anxiety would be independent predictors of mathematics anxiety; (5) that females would show more mathematics anxiety and more test anxiety than males; (6) that males and females would not differ in actual mathematical performance or in working memory; (7) that gender differences in mathematical performance would reduce after controlling for test anxiety; (8) that science students would perform better than humanities students on mathematics measures; (9) that science students would show higher mathematics anxiety than humanities students; (10) that science students would show higher working memory than humanities students; and (11) that differences between science and humanities students would reduce after controlling for working memory.

\section{MATERIALS AND METHODS}

\section{Design}

A between-participants design was used. The grouping factors were gender (male vs. female) and subject of study (sciences vs. humanities). There were five dependent variables: two different mathematics test scores, digit span, mathematics anxiety, and test anxiety. Participants were selected to ensure equal numbers of participants falling into each of the grouping categories.

\section{Participants}

Participants were 40 University Undergraduates aged 18-25. Ten were males studying sciences, 10 females studying sciences, 10 males studying humanities, and 10 females studying 
humanities. University subjects were classed as sciences or humanities on the basis of the division in which the university classed them: sciences if classed in the Medical Sciences division or Mathematical, Physical and Life Sciences division; and humanities if classed in the Humanities division or Social Sciences division.

Participants were recruited through advertisement via email and social media and through social contacts and word-of-mouth. They were given an information sheet about the tasks that they would be given and then signed a consent form.

Ethical approval was sought and granted by the Central University Research Ethics Committee of Oxford University.

\section{Tasks}

\section{Attitude Measures}

1. A measure of Test Anxiety. The measure used was Sarason's (1977) Test Anxiety Scale. This had been shown to have test-retest reliability scores in the 0.80 (Zeidner and Matthews, 2003). It has also been found to correlate well with other test anxiety scales, indicating good concurrent validity. In the present study, Cronbach's alpha for this measure was 0.91 .

2. A measure of attitudes to mathematics. The measure used was Aiken's (1974) Mathematics Enjoyment scale. This test had a Cronbach alpha of 0.95 in Aiken's (1974) original study; 0.88 in Watson's (1983) validation; and 0.87 in the sample tested in the present study. Both Aiken (1974) and Watson's (1983) obtained highly significant correlations with a range of measures of mathematical performance and attitudes to mathematics, indicating good concurrent validity.

\section{Working Memory Test}

3. WAIS Digit Span subtest. This was taken from the Wechsler Adult Intelligence Scale-IV (Wechsler, 2008). This involves repeating strings of numbers forward and backward. For the purpose of the present study, the Backward Digit Span was used, as this is a purer measure of working memory.

\section{Mathematics Tests}

4. WAIS Arithmetic subtest (Wechsler, 2008). This was taken from the Wechsler Adult Intelligence Scale-III. It is an orally presented test of word problem-solving with an oral response. The scaled score was the measure used in the analysis. Cronbach's alpha was 0.9 both in the original standardization and in the present study.

5. Test 2 of Hitch's (1978a) Numerical Abilities Tests. This was a written test, involving mathematical questions on fractions, decimals, percentages, and arithmetic functions. Participants were given up to $20 \mathrm{~min}$ to complete this without a calculator. In the original study, the split-half reliability computed by the Spearman-Brown formula was 0.97. In the present study, Cronbach's alpha was 0.95.

\section{Procedure}

Participants were asked to read an information sheet and sign a consent form and were then told the tasks they were going to complete. Participants were given these tasks in a quiet room with only the researcher present. They were first given the Backward Digit Span and WAIS Arithmetic test (Wechsler, 2008). They were then given the Test Anxiety scale and then the Mathematics Enjoyment Scale, untimed. These were presented on paper, and participants were asked to complete them by hand. Finally, participants were given the Written mathematics test. The decision was made to put the Written mathematics test last, so that self-perceived performance on it would not impact responses given on the attitude measures.

\section{Analysis}

IBM SPSS Version 25 was used to analyze the data (SPSS, IBM, 2017).

\section{RESULTS}

Scaled scores were coded for Arithmetic using the scoring guide in the WAIS scoring manual (Wechsler, 2008). Since only Backward Digit Span and not Forward Digit Span was included in the analyses for this study, no scaled score was coded for Digit Span.

Arithmetic raw scores ranged from 12 to $21 \quad(M=17.93$, $S D=1.94)$ and scaled scores from 10 to $17(M=8.45, S D=2.3)$. Written mathematics test scores ranged from $19 / 40$ to $40 / 40$ $(M=33.25, S D=6.03)$. Backward Digit Span scores ranged from 5 to $13(M=20.30, S D=3.94)$. Test anxiety scores ranged from 4 to $27(M=15.15, S D=5.13)$. Mathematics Anxiety/Enjoyment scores ranged from 12 to $48(M=25.58, S D=11.53)$.

\section{Pearson's Correlations}

Pearson's correlations were examined between Arithmetic scaled score, Written Mathematics test score, Backward Digit Span, Test Anxiety, and Mathematics Anxiety/Enjoyment. These correlations are shown in Table 1 . The correlation between Arithmetic scaled score and Written mathematics test score did not reach significance $(p=0.07)$. Backward Digit Span correlated significantly with Arithmetic scaled score, but not with Written mathematics test score. Mathematics Anxiety/Enjoyment correlated significantly with all the other variables: positively with test anxiety and negatively with backward digit span, arithmetic scaled score and written Mathematics test score. Test anxiety only correlated with Mathematics Anxiety/Enjoyment.

\section{Multiple Regressions}

An entry-type multiple regression was carried out with Arithmetic scaled score as the dependent variables, and Backward Digit Span, Test Anxiety and Mathematics Anxiety/Enjoyment as the predictors. $R^{2}$ was 0.17 . The model did not explain a significant amount of the variance $[F(3,36)=2,5 ; p=0.07]$. None of the individual predictors was significant for Arithmetic scaled score: Neither Backward Digit Span, $\beta=0.22, t(3,37)=1.26$, 
$p=0.217$; Test Anxiety, $\beta=-0.038, t(3,37)=-1.69, p=0.834$, nor Mathematics Anxiety/Enjoyment, $\beta=-0.28, \quad t(3,37)=-1.45$, $p=0.15$ proved significant.

Another entry-type multiple regression was carried out with Written mathematics test score as the dependent variable, and Backward Digit Span, Test Anxiety and Mathematics Anxiety/ Enjoyment as the predictors. $R^{2}$ was 0.14 . The model did not explain a significant amount of the variance $[F(3,36)=1,97$; $p=0.135]$. None of the individual predictors was significant for Written mathematics test score: Neither Backward Digit Span, $\beta=0.17, t(3,37)=0.95, p=0.347$; Test Anxiety, $\beta=-0.33$, $t(3,37)=-0.18, p=0.838$, nor Mathematics Anxiety/Enjoyment, $\beta=-0.266, t(3,37)=-136, p=0.18$ proved significant.

Another entry-type multiple regression was carried out with Mathematics Anxiety/Enjoyment score as the dependent variable, and Backward Digit Span, Test anxiety and Arithmetic scaled score as the predictors. $R^{2}$ was 0.42 . The model explained a highly significant amount of the variance $[F(3,36)=8,81$; $p<0.001]$. Backward Digit Span was a highly significant predictor $\beta=-0.385, t(3,37)=-2.79, p=0.008$; as was Test Anxiety, $\beta=0.462, t(3,37)=3.51 ; p=0.001$. Arithmetic scaled score was not a significant predictor, $\beta=0.199, t(3,37)=-1.45 ; p=0.156$.
Another entry-type multiple regression was carried out with Mathematics Anxiety/Enjoyment score as the dependent variable, and Backward Digit Span, Test anxiety and Written mathematics test score as the predictors. $R^{2}$ was 0.41 . The model explained a highly significant amount of the variance $[F(3,36)=8,32$; $p<0.001]$. Backward Digit Span was a highly significant predictor $\beta=-0.4, t(3,37)=-2.95, p=0.006$; as was Test Anxiety, $\beta=0.466, t(3,37)=3.55 ; p=0.001$. Written mathematics test score was not a significant predictor, $\beta=-0.18, t(3,37)=1.36 ; p=0.183$.

\section{Analyses of Variance}

A two-factor between-participants Analysis of Variance was then conducted, with Gender (Male vs. Female) and Subject of Study (Science vs. Humanities) as the grouping factors and Arithmetic scaled score, Written mathematics test score. Backward Digit Span, Test Anxiety, and Mathematics Anxiety/Enjoyment as the dependent variables.

As Table 2 indicates, there were significant gender differences in both Test Anxiety and Mathematics Anxiety: females scored higher on both. There were no significant gender differences in either mathematical performance measure or on Backward Digit Span. There were significant course differences, with

TABLE 1 | Pearson's correlations for arithmetic scaled score, written mathematics test score, backward digit span, test anxiety, and mathematics anxiety/enjoyment.

\begin{tabular}{|c|c|c|c|c|c|}
\hline Arithmetic Scaled Score & - & $0.26(p=0.1)$ & $0.3(p=0.06)$ & $0.09(p=0.46)$ & $-0.379 *(p=0.016)$ \\
\hline Backward Digit Span & - & - & - & $0.163(p=0.316)$ & $-0.37 *(p=0.018)$ \\
\hline Test Anxiety & - & - & - & - & $0.423 * *(p=0.007)$ \\
\hline
\end{tabular}

$* p<0.05 ; * * p<0.01$

TABLE 2 | Results of analysis of variance with gender and course as grouping factors and arithmetic scaled score, written mathematics test score, backward digit span.

\begin{tabular}{|c|c|c|c|c|c|c|}
\hline Source & Dependent Variable & df & Mean Square & $\boldsymbol{F}$ & Sig. & Partial Eta Squared \\
\hline \multirow[t]{5}{*}{ Gender } & $\begin{array}{l}\text { Arithmetic Scaled } \\
\text { Score }\end{array}$ & $(1,36)$ & 0.625 & 0.182 & 0.672 & 0.005 \\
\hline & Written Mathematics & $(1,36)$ & 6.400 & 0.217 & 0.644 & 0.006 \\
\hline & Backward Digit Span & $(1,36)$ & 0.100 & 0.020 & 0.889 & 0.001 \\
\hline & Test Anxiety & $(1,36)$ & 108.900 & 4.477 & 0.041 & 0.111 \\
\hline & $\begin{array}{l}\text { Mathematics Anxiety/ } \\
\text { Enjoyment }\end{array}$ & $(1,36)$ & 632.025 & 6.722 & 0.014 & 0.157 \\
\hline \multirow[t]{5}{*}{ Course } & $\begin{array}{l}\text { Arithmetic Scaled } \\
\text { Score }\end{array}$ & $(1,36)$ & 3.025 & 0.883 & 0.354 & 0.024 \\
\hline & Written Mathematics & $(1,36)$ & 348.100 & 11.807 & 0.002 & 0.247 \\
\hline & Backward Digit Span & $(1,36)$ & 22.500 & 4.480 & 0.041 & 0.111 \\
\hline & Test Anxiety & $(1,36)$ & 0.100 & 0.004 & 0.949 & 0.000 \\
\hline & $\begin{array}{l}\text { Mathematics Anxiety/ } \\
\text { Enjoyment }\end{array}$ & $(1,36)$ & 950.625 & 10.110 & 0.003 & 0.219 \\
\hline \multirow[t]{5}{*}{ Gender * Course } & $\begin{array}{l}\text { Arithmetic Scaled } \\
\text { Score }\end{array}$ & $(1,36)$ & 0.025 & 0.007 & 0.932 & 0.000 \\
\hline & Written Mathematics & $(1,36)$ & 1.600 & 0.054 & 0.817 & 0.002 \\
\hline & Backward Digit Span & $(1,36)$ & 2.500 & 0.498 & 0.485 & 0.014 \\
\hline & Test Anxiety & $(1,36)$ & 2.500 & 0.103 & 0.750 & 0.003 \\
\hline & $\begin{array}{l}\text { Mathematics Anxiety/ } \\
\text { Enjoyment }\end{array}$ & $(1,36)$ & 216.225 & 2.300 & 0.138 & 0.060 \\
\hline
\end{tabular}

Test anxiety and mathematics anxiety/enjoyment as the dependent variables. 
moderate effect size, for Written Mathematics (science students did better) and Mathematics Anxiety (humanities students scored higher), and one with lower effect size for Backward Digit Span (science students had longer spans). There were no significant interactions between course and gender. However, it should be noted that although Table 3 supports the lack of interaction between course and gender regarding the mean Mathematics Anxiety/Enjoyment scores, the standard deviation was much lower for male science students than for female science students or for humanities students of either gender.

In order to investigate whether Test Anxiety was driving the results for gender differences and similarities, a one-way

TABLE 3 | Scores by gender and course for arithmetic (scaled score), written mathematics, backward digit span, test anxiety, and mathematics anxiety/enjoyment.

\begin{tabular}{|c|c|c|c|c|c|}
\hline & Gender & Course & Mean & $\begin{array}{c}\text { Std. } \\
\text { Deviation }\end{array}$ & $\mathbf{N}$ \\
\hline \multirow{9}{*}{$\begin{array}{l}\text { Arithmetic } \\
\text { Scaled } \\
\text { Score }\end{array}$} & \multirow[t]{3}{*}{ Male } & Science & 14.4000 & 1.26491 & 10 \\
\hline & & Hum. & 13.8000 & 2.25093 & 10 \\
\hline & & Total & 14.1000 & 1.80351 & 20 \\
\hline & \multirow[t]{3}{*}{ Female } & Science & 14.1000 & 1.66333 & 10 \\
\hline & & Hum. & 13.6000 & 2.06559 & 10 \\
\hline & & Total & 13.8500 & 1.84320 & 20 \\
\hline & \multirow[t]{3}{*}{ Total } & Science & 14.2500 & 1.44641 & 20 \\
\hline & & Hum. & 13.7000 & 2.10513 & 20 \\
\hline & & Total & 13.9750 & 1.80438 & 40 \\
\hline \multirow{9}{*}{$\begin{array}{l}\text { Written } \\
\text { Mathematics }\end{array}$} & \multirow[t]{3}{*}{ Male } & Science & 36.80 & 3.521 & 10 \\
\hline & & Hum. & 30.50 & 6.721 & 10 \\
\hline & & Total & 33.65 & 6.141 & 20 \\
\hline & \multirow[t]{3}{*}{ Female } & Science & 35.60 & 4.502 & 10 \\
\hline & & Hum. & 30.10 & 6.332 & 10 \\
\hline & & Total & 32.85 & 6.046 & 20 \\
\hline & \multirow[t]{3}{*}{ Total } & Science & 36.20 & 3.982 & 20 \\
\hline & & Hum. & 30.30 & 6.359 & 20 \\
\hline & & Total & 33.25 & 6.029 & 40 \\
\hline \multirow{9}{*}{$\begin{array}{l}\text { Backward } \\
\text { Digit Span }\end{array}$} & \multirow[t]{3}{*}{ Male } & Science & 8.90 & 1.524 & 10 \\
\hline & & Hum. & 7.90 & 2.514 & 10 \\
\hline & & Total & 8.40 & 2.088 & 20 \\
\hline & \multirow[t]{3}{*}{ Female } & Science & 9.50 & 2.121 & 10 \\
\hline & & Hum. & 7.50 & 2.635 & 10 \\
\hline & & Total & 8.50 & 2.544 & 20 \\
\hline & \multirow[t]{3}{*}{ Total } & Science & 9.20 & 1.824 & 20 \\
\hline & & Hum. & 7.70 & 2.515 & 20 \\
\hline & & Total & 8.45 & 2.298 & 40 \\
\hline \multirow[t]{9}{*}{ Test Anxiety } & \multirow[t]{3}{*}{ Male } & Science & 13.20 & 3.706 & 10 \\
\hline & & Hum. & 13.80 & 4.290 & 10 \\
\hline & & Total & 13.50 & 3.914 & 20 \\
\hline & \multirow[t]{3}{*}{ Female } & Science & 17.00 & 6.515 & 10 \\
\hline & & Hum. & 16.60 & 4.766 & 10 \\
\hline & & Total & 16.80 & 5.559 & 20 \\
\hline & \multirow[t]{3}{*}{ Total } & Science & 15.10 & 5.515 & 20 \\
\hline & & Hum. & 15.20 & 4.641 & 20 \\
\hline & & Total & 15.15 & 5.031 & 40 \\
\hline \multirow{9}{*}{$\begin{array}{l}\text { Mathematics } \\
\text { Anxiety/ } \\
\text { Enjoyment }\end{array}$} & \multirow[t]{3}{*}{ Male } & Science & 14.4000 & 1.89737 & 10 \\
\hline & & Hum. & 28.8000 & 11.24278 & 10 \\
\hline & & Total & 21.6000 & 10.77717 & 20 \\
\hline & \multirow[t]{3}{*}{ Female } & Science & 27.0000 & 10.77033 & 10 \\
\hline & & Hum. & 32.1000 & 11.40614 & 10 \\
\hline & & Total & 29.5500 & 11.10938 & 20 \\
\hline & \multirow[t]{3}{*}{ Total } & Science & 20.7000 & 9.92127 & 20 \\
\hline & & Hum. & 30.4500 & 11.15194 & 20 \\
\hline & & Total & 25.5750 & 11.52898 & 40 \\
\hline
\end{tabular}

ANOVA was carried out, with Gender as the grouping factor, Test Anxiety as a covariate, and Arithmetic scaled score, Written mathematics test score, Backward Digit Span, and Mathematics Anxiety/Enjoyment as the dependent variables. Test Anxiety proved to be a significant covariate for Mathematics Anxiety/ Enjoyment, $F(1,37)=5.07, p=0.03, \eta_{p}^{2}=0.12$. There were now no significant gender differences in any variable, including Mathematics Anxiety/Enjoyment.

In order to investigate whether working memory was driving the results for course differences, a similar one-way ANOVA was carried out, with Course as the grouping factor, Backward Digit Span as a covariate, and Arithmetic scaled score, Written mathematics test score, Test Anxiety, and Mathematics Anxiety. Backward Digit Span was not a significant covariate for any of the dependent variables. Course differences continued to be significant for Written mathematics test score, $F(1,37)=5.07$, $p=0.004, \eta_{p}^{2}=0.201$ and for Mathematics Anxiety/Enjoyment, $F(1,37)=5.11, p=03, \eta_{p}^{2}=0.121$.

As the ANOVAs may have been somewhat underpowered due to the small sample size, they were supplemented with Bayesian analyses. Table 4 shows a Bayesian independent samples test for gender comparisons for Arithmetic scaled score, Written mathematics test score, Backward Digit Span, Test Anxiety, and Mathematics Anxiety/Enjoyment.

As can be seen, the Bayes factor was high, favoring the null hypothesis, for the mathematical performance measures and Backward Digit Span, but much lower, giving greater support to the alternative hypothesis, for both anxiety measures.

Table 5 shows a Bayesian independent samples test for course comparisons for Arithmetic scaled score, Written mathematics test score, Backward Digit Span, Test Anxiety, and Mathematics Anxiety/Enjoyment.

As can be seen, the Bayes factor was high, favoring the null hypothesis, for Arithmetic Scaled Score and Test Anxiety, but much lower, giving greater support to the alternative hypothesis, for Written Mathematics, Backward Digit Span, and Mathematics Anxiety/Enjoyment. Thus, the results of the Bayesian analyses are concordant with those of the Analyses of Variance.

\section{DISCUSSION}

The results of this study confirm our first hypothesis and support many previous studies (Hembree, 1990; Ma and Kishor, 1997; Carey et al., 2016; Dulaney et al., 2017; Skagerlund et al., 2019; Zhang et al., 2019; Abín et al., 2020; Barroso et al., 2021; Caviola et al., 2021) in suggesting that there are some significant relationships between attitudes and performance. A mathematics anxiety and enjoyment measure correlated significantly with two different measures of mathematics: the WAIS Arithmetic subtest (Wechsler, 2008), which mainly tested oral arithmetic problem-solving involving relatively simple calculations and Hitch's (1978a) Numerical Abilities Test 2, which mainly tested written, more complex calculations, and the understanding of fractions and percentages. The fact that it correlated with both simpler and more complex calculations suggests that its effect may be broader than that proposed by 
TABLE 4 | Bayes factor independent sample test for differences between male and females (method=rouder) ${ }^{\mathrm{a}}$.

\begin{tabular}{|c|c|c|c|c|c|c|}
\hline & Mean Difference & $\begin{array}{c}\text { Pooled Std. Error } \\
\text { Difference }\end{array}$ & Bayes Factor ${ }^{b}$ & $t$ & df & Sig.(2-tailed) \\
\hline $\begin{array}{l}\text { Arithmetic Scaled } \\
\text { Score }\end{array}$ & -0.2500 & 0.57663 & 3.962 & -0.434 & 38 & 0.667 \\
\hline Written Mathematics & -0.80 & 1.927 & 3.990 & -0.415 & 38 & 0.680 \\
\hline Backward Digit Span & 0.10 & 0.736 & 4.269 & 0.136 & 38 & 0.893 \\
\hline Test Anxiety & 3.30 & 1.520 & 0.596 & 2.171 & 38 & 0.036 \\
\hline $\begin{array}{l}\text { Mathematics Anxiety/ } \\
\text { Enjoyment }\end{array}$ & 7.9500 & 3.46097 & 0.476 & 2.297 & 38 & 0.027 \\
\hline
\end{tabular}

${ }^{a}$ Assumes unequal variance between groups.

${ }^{b}$ Bayes factor: Null vs. alternative hypothesis.

TABLE 5 | Bayes factor independent sample test for differences between science and humanities students (Method=Rouder) ${ }^{\mathrm{a}}$.

\begin{tabular}{|c|c|c|c|c|c|c|}
\hline & Mean Difference & $\begin{array}{l}\text { Pooled Std. Error } \\
\text { Difference }\end{array}$ & Bayes Factor ${ }^{\mathrm{b}}$ & $t$ & df & Sig. (2-tailed) \\
\hline $\begin{array}{l}\text { Arithmetic Scaled } \\
\text { Score }\end{array}$ & -0.5500 & 0.57113 & 2.870 & -0.963 & 38 & 0.342 \\
\hline Written Mathematics & -5.90 & 1.678 & 0.035 & -3.517 & 38 & 0.001 \\
\hline Backward Digit Span & -1.50 & 0.695 & 0.608 & -2.159 & 38 & 0.037 \\
\hline Test Anxiety & 0.10 & 1.612 & 4.297 & 0.062 & 38 & 0.951 \\
\hline $\begin{array}{l}\text { Mathematics Anxiety/ } \\
\text { Enjoyment }\end{array}$ & 9.7500 & 3.33764 & 0.137 & 2.921 & 38 & 0.006 \\
\hline
\end{tabular}

${ }^{a}$ Assumes unequal variance between groups.

${ }^{b}$ Bayes factor: Null vs. alternative hypothesis.

Abín et al. (2020), whose results suggested that mathematics anxiety is related to complex but not simple arithmetic, though it must be remembered that Abín et al. (2020) used different measures to ours for both mathematics performance and mathematics anxiety. The meta-analysis by Namkung et al. (2019) also suggested that mathematics anxiety is much more related to complex than simple arithmetic.

As predicted mathematics performance, correlated with working memory; but this only applied to Arithmetic scaled score and not to performance on the written arithmetic test. This may reflect the fact that verbal rehearsal is likely to be more important to oral than written arithmetic (Hitch, 1978b). Also as predicted, Test Anxiety correlated significantly with Mathematics Anxiety/Enjoyment. However, contrary to predictions, it did not correlate with either of with the mathematics measures. It also did not correlate with the working memory measure.

Contrary to predictions, neither working memory, test anxiety nor Mathematics Anxiety/Enjoyment was a significant independent predictor of either of the mathematics measures in multiple regressions. On the other hand, both working memory and test anxiety, but neither of the mathematics performance measures, were significant predictors of Mathematics Anxiety/Enjoyment.

Thus, the mathematics performance measures seemed to be relatively independent of working memory (though this did correlate with Arithmetic scaled score), test anxiety, and even of one another. This differs somewhat from the findings of some other studies, which found stronger influences on mathematical performance of test anxiety (Devine et al., 2012) of working memory (Skagerlund et al., 2019; Caviola et al., 2021) and especially of mathematics anxiety (Ma and Kishor, 1997; Dulaney et al., 2017; Skagerlund et al., 2019; Zhang et al., 2019; Barroso et al., 2021; Caviola et al., 2021). The findings here probably correspond most to those of Douglas and LeFevre (2018), who found relatively limited influence of working memory on other factors and their interrelationships. However, Mathematics Anxiety/Enjoyment did, as pointed out earlier, correlate with all the other variables, even though it did not independently predict and was not independently predicted by most of them, and it was independently predicted by both working memory and test anxiety. The fact that working memory was a significant independent predictor of attitudes to mathematics, to a greater extent than actual mathematical performance, is one of the most striking findings of the present study. Future research should investigate the direction of causation. It has tended to be assumed that mathematics anxiety interferes with working memory, but it is also possible that working memory weaknesses contribute to mathematics anxiety by increasing the frequency of instances of distraction, confusion, and private and public failures.

As predicted, the ANOVA showed that females and males did not differ in measures of mathematics performance, but females showed more negative attitudes to mathematics, as well as higher levels of test anxiety. These findings are consistent with numerous previous findings, for example, Devine et al. (2012). The lack of a gender difference in performance supports ideas that differences in mathematics anxiety are not explainable by actual poorer performance and may result from exposure to gender stereotypes. They may also reflect differences in 
academic performance anxiety more generally, a possibility supported by the finding that gender differences in mathematics anxiety ceased to be significant when test anxiety was introduced as a covariate. Future studies should investigate differences in attitudes to and anxiety about academic subjects other than mathematics, including subjects, such as English, where females are generally regarded as higher performing than males. It may also be that different science subjects may be associated with different levels of mathematics anxiety and enjoyment. Some sciences are known to be predominantly chosen by female students (e.g., biology and psychology) and others to be predominantly chosen by male students (e.g., physics and engineering), and it is possible that the latter are seen as "more mathematical."

The study partially supported the hypothesis that science students would perform better at mathematics than humanities students; they scored higher on the written mathematics test than humanities students, but the two groups of students did not differ in Arithmetic scaled score. Science students reported more positive attitudes to mathematics than did humanities students. This finding is unsurprising because, not only are high level mathematical skills required for entry onto most science degree courses, but those who enjoy mathematics are more likely to select such courses. However, the difference in attitudes was very striking, especially as all the participants, as students at a highly selective university, would have needed to have good mathematics qualifications at $16+$, and therefore, people with strongly negative attitudes would have been less likely to be participants in the first place. Unlike the gender difference, this difference applied to mathematics anxiety only, and not to general test anxiety. It is also notable that, though there was no significant coursegender interaction for mean mathematics anxiety scores, male science students appeared to be more homogeneous in their (lack of) mathematics anxiety than the other groups, showing a very low standard deviation.

One of the most striking findings was that science students had longer digit spans, implying better working memory, than the humanities students. It would be of interest to investigate whether this is the case for all sciences or just for some and whether humanities students might do better on tests of longterm memory, as their subjects may involve less need for keeping track of ongoing experimental results and more need to remember information long-term. The present findings are consistent with those of Popescu et al. (2019), who found that mathematics graduate students scored higher on backward digit span and on another working memory task (forward letter span) than humanities graduate students.

Despite the differences in working memory between people doing science and humanities courses, working memory was not driving the differences between courses, as it was not a significant covariate in the ANOVA comparing students taking different courses on attitude and performance measures; and the course differences in written arithmetic and Mathematics Enjoyment/Anxiety were not affected by its inclusion as a covariate.

The most significant limitation to the present study is of course the relatively small sample of 40 participants. Most findings were either clearly significant or non-significant, and there were few of the borderline and near-significant results that can result from underpowering, with the exception of the 0.3 correlation $(p=0.06)$ between Arithmetic Scaled Score and Backward Digit Span, However, it is still possible that some potentially significant associations were not found due to the relatively small sample size and that this may partially explain the limited number of independent predictors found. Future studies should attempt to replicate the findings with larger sample.

Ideally, such a sample should also be more diverse. As is commonly true of studies of adults, the results may be to some degree biased by the fact that the available participants were university students. Thus, it is likely that they were more able mathematically and had more positive attitudes than the general population. For example, no participant obtained an Arithmetic scaled score lower than 10, which represents average performance. It would be desirable to study relationships between mathematics attitudes, mathematics performance, and working memory in a larger and more varied, less self-selected sample; though in any sample, people with severe levels of mathematics anxiety are more likely to decline to participate. The participants in this study were informed in advance about what the study would involve, including a mathematics task. This was deemed necessary for ethical reasons, as important for obtaining informed consent; but it may have deterred people with high levels of mathematics anxiety.

It would also be desirable for future studies to include measures of motivation, which may help to explore the possibility that there is not always a simple linear negative relationship between mathematics performance and mathematics anxiety. Macher et al. (2015) have suggested that anxiety may not always be associated with poor performance, at least in the case of statistics anxiety. They proposed that statistics anxiety may on the one hand, both disrupt performance on the other hand may increase motivation to avoid failure, leading for example to greater preparation for examinations. Wang et al. (2015) found that the relationship between mathematics anxiety and mathematics performance could vary with students' level of intrinsic motivation toward mathematics. Students with low intrinsic motivation showed a negative relationship between mathematics anxiety and performance. Students with high intrinsic motivation showed an inverted U-shaped relationship between mathematics anxiety and performance: performing best when moderately anxious and least well when either highly anxious or showing very little anxiety.

In any case, it seems that the relationship between mathematics anxiety and mathematical performance is not always simple, especially if motivation is included as a variable. Wang et al. (2018) carried out a further study of over 900 high school students, including profile analysis of combinations of dimensions of mathematics anxiety and mathematics motivation. They found eight different profiles, with different types of associations with mathematics achievement and engagement. For instance, the highest achieving students reported modest examinationrelated mathematics anxiety and high mathematics motivation, 
while the most engaged students reported both high examinationrelated mathematics anxiety and high mathematics motivation.

As stated in the Introduction, the use of Aiken (1974) Mathematics Enjoyment Scale had the advantages of taking relatively little time and of measuring positive as well as purely negative reactions to mathematics, which reduced the chance of ceiling effects in a relatively mathematically able population. However, one problem with the use of a single scale to measure attitudes and emotions toward mathematics is that it makes it more difficult to differentiate between the effects on mathematical performance, and interactions with working memory, of different attitudes and emotions regarding mathematics. In the present paper, "attitudes to mathematics," "mathematics anxiety" and "mathematics enjoyment/anxiety" have been used almost interchangeably to refer to negative reactions to mathematics. The use of more diverse measures might facilitate a more nuanced analysis. Since some other studies have suggested that positive emotions toward mathematics predict performance, even after controlling for anxiety (Pinxten et al., 2014; Villavicencio and Bernardo, 2016), it would be interesting to investigate whether different aspects of attitudes and emotions regarding mathematics have different effects on mathematics performance This could involve having separate scales for mathematics anxiety and mathematics enjoyment, and/or incorporating and investigating a range of components of mathematics anxiety and other attitudes and emotions, as is done to varying degrees in, for example, the Mathematics Anxiety Rating Scale (Richardson and Suinn, 1972) and the Fennema-Sherman mathematics attitude scales (Fennema and Sherman, 1976).

There is also the question of how closely attitudes and emotional reactions to mathematics are related, and which of these has the strongest relationship to mathematical performance. Some researchers have suggested that mathematics anxiety has both a cognitive dimension (performance anxiety) and an affective dimension (fearful emotional reactions to mathematical stimuli; Wigfield and Meece, 1988; Sorvo et al., 2017). Some studies suggest that the cognitive dimension is not strongly related to mathematical performance before secondary school age, while the affective dimension is already significantly related to performance in the primary school years (Sorvo et al., 2017). Interestingly, Chen et al. (2018) found that, in a group of elementary school children, attitudes to mathematics were not associated with affective-motivational brain areas, which may indicate that, at least in the early stages of development, attitudes to mathematics are distinct from emotions. It may also indicate that, as several studies have suggested, younger children have more positive attitudes to mathematics than older children and adults and have relatively low levels of mathematics anxiety (e.g., Hembree, 1990; Dowker et al., 2012; Szczygieł and Pieronkiewicz, 2021). Chen et al. (2018) found that in elementary school children, the positive attitudes were associated with enhanced hippocampal activation. They proposed that positive attitudes might influence memory processes in mathematics. Therefore, they suggested that attitudes might influence memory processes during learning activities and task solving.
Some studies have suggested that self-rating may be a stronger predictor of mathematical performance than either anxiety or enjoyment in both primary and secondary school children (Dowker et al., 2012; Van der Beek et al., 2017). It can be difficult to determine the causal direction: part of the relationship could be because individuals are in fact estimating their performance accurately and may for example be rating their performance on the basis of previous test scores. However, even in longitudinal studies, confidence seems to predict future performance (Pinxten et al., 2014). Therefore, future studies should include measure of confidence/ self-rating in mathematics.

Therefore, it would be useful to replicate the current study in school children, preferably longitudinally and starting in primary school, to see how the relationships between these variables change over time, as suggested by Vukovic et al. (2013). An important aim would be to see if there is a particular point in childhood where the relationship between mathematics anxiety and mathematics performance typically begin to show a strong correlation. If so, it would be desirable to intervene in either mathematics performance or mathematics anxiety or both, before the development of a vicious circle, which may be hard to break; and, if possible, to create a virtuous circle instead. For example (Supekar et al., 2015) found that a mathematics intervention for young children not only improved mathematical performance but reduced anxiety. There are still fewer interventions for mathematics anxiety than for mathematical performance, and it is important to do more work on developing them (Moustafa et al., 2021). It may be that one next step would be to develop interventions simultaneously targeting both performance and anxiety.

To summarize: the results of the present study suggest that mathematics anxiety is correlated with both simple oral arithmetic and complex written arithmetic, but that it ceases to be a significant predictor of either type of arithmetic when test anxiety and working memory are included with it in a multiple regression. However, test anxiety was neither a significant correlate nor significant independent predictor of either mathematics measure. Working memory was a significant independent predictor of oral but not written arithmetic. In multiple regressions with mathematics anxiety as the dependent variable, it was significantly predicted by both working memory and test anxiety, but not by either measure of mathematical performance. There were no gender differences in oral or written arithmetic or in working memory, but females showed more test anxiety and more mathematics anxiety. There were signs that test anxiety was driving the gender differences in mathematics anxiety, as gender differences in mathematics anxiety ceased to be significant when test anxiety was included as a covariate. As regards course, science students had lower mathematics anxiety than humanities students, but the groups did not differ in test anxiety, Science students were better at written but not mental arithmetic. They were also better at working memory, but this was not a significant covariate and did not appear to be influencing the group differences in written mathematics and mathematics anxiety. 


\section{DATA AVAILABILITY STATEMENT}

The raw data supporting the conclusions of this article will be made available by the authors, without undue reservation.

\section{ETHICS STATEMENT}

The studies involving human participants were reviewed and approved by Central University Research Ethics Committee, Oxford University. The patients/participants provided their written informed consent to participate in this study.

\section{REFERENCES}

Abín, A., Núñez, J. C., Rodríguez, C., Cueli, M., García, T., and Rosário, P. (2020). Predicting mathematics achievement in secondary education: The role of cognitive, motivational, and emotional variables. Front. Psychol. 11:876. doi: $10.3389 /$ fpsyg.2020.00876

Aiken, L. R. (1974). Two scales of attitude toward mathematics. J. Res. Math. Educ. 5, 67-71. doi: 10.5951/jresematheduc.5.2.0067

Ashcraft, M. H. (2002). Math anxiety: personal, educational, and cognitive consequences. Curr. Dir. Psychol. Sci. 11, 181-185. doi: 10.1111/14678721.00196

Ashcraft, M. H., and Kirk, E. P. (2001). The relationships between working memory, math anxiety and performance. J. Exp. Psychol. General 130, 224-237. doi: 10.1037/0096-3445.130.2.224

Ashcraft, M. H., Kirk, E. P., and Hopko, D. (1998). "On the cognitive consequences of mathematics anxiety," in The Development of Mathematical Skills. ed. C. Donlan (Hove: Erlbaum), 175-196.

Ashcraft, M. H., and Ridley, K. S. (2005). "Math anxiety and its cognitive consequences: a tutorial review," in The Handbook of Mathematical Cognition. ed. J. I. D. Campbell (New York, NY: Psychology Press), 315-327.

Barroso, C., Ganley, C. M., McGraw, A. L., Geer, E. A., Hart, S. A., and Daucourt, M. C. (2021). A meta-analysis of the relation between math anxiety and math achievement. Psychol. Bull. 147, 134-168. doi: 10.1037/ bul0000307

Beilock, L. S., and DeCaro, M. S. (2007). From poor performance to success under stress: working memory, strategy selection, and mathematical problem solving under pressure. J. Exp. Psychol. 33, 983-998. doi: 10.1037/02787393.33.6.983

Betz, N. E. (1978). Prevalence, distribution, and correlates of math anxiety in college students. J. Couns. Psychol. 25, 441-448. doi: 10.1037/0022-0167.25.5.441

Birgin, O., Baloglu, M., Catlioglu, H., and Gurbuz, R. (2010). An investigation of mathematics anxiety among sixth through eighth grade students in Turkey. Learn. Individ. Differ. 20, 654-658. doi: 10.1016/j.lindif.2010.04.006

Carey, E., Hill, F., Devine, A., and Szucs, D. (2016). The chicken or the egg? The direction of the relationship between mathematics anxiety and mathematics performance. Front. Psychol. 6:1987. doi: 10.3389/fpsyg.2015.01987

Caviola, S., Mammarella, I. C., Lucangeli, D., and Cornoldi, C. (2012). The involvement of working memory in children's exact and approximate mental additions. J. Exp. Child Psychol. 112, 141-160. doi: 10.1016/j. jecp.2012.02.005

Caviola, S., Toffalini, E., Giofre, D., Ruiz, J. M., Szucs, D., and Mammarrella, I. C. (2021). Math performance and academic anxiety forms, from sociodemographic to cognitive aspects: A meta-analysis on 906, 311 participants. Educ. Psychol. Rev. 1-37. doi: 10.1007/s10648-021-09618-5

Chen, L., Bae, S. R., Battista, C., Qin, S., Chen, T., Evans, T. M., et al. (2018). Positive attitude toward math supports early academic success: behavioral evidence and neurocognitive mechanisms. Psychol. Sci. 29, 390-402. doi: 10.1177/0956797617735528

Ching, B. H.-H. (2017). Mathematics anxiety and working memory: longitudinal associations with mathematical performance in Chinese children. Contemp. Educ. Psychol. 51, 99-113. doi: 10.1016/j.cedpsych.2017.06.006

\section{AUTHOR CONTRIBUTIONS}

$\mathrm{AD}$ was predominantly responsible for designing the study and HS for carrying out the experiments. All authors contributed equally to analyses and wrote the article.

\section{FUNDING}

This research was partly based on a student project, which was funded by the Oxford University Department of Experimental Psychology.

Delage, V., Trudel, G., Retanal, F., and Maloney, A. (2021). Spatial anxiety and spatial ability: Mediators of gender differences in math anxiety. J. Exp. Psychol. General. doi: 10.1037/xge0000884 [Epub Ahead of Print]

Devine, A., Fawcett, K., Szucs, D., and Dowker, A. (2012). Gender differences in mathematics anxiety and the relation to mathematics performance while controlling for test anxiety. Brain Behav. Func. 8:33. doi: 10.1186/1744-9081-8-33

Dew, K., Galassi, J., and Galassi, M. (1983). Mathematics anxiety: some basic issues. J. Couns. Psychol. 30, 443-446. doi: 10.1037/0022-0167.30.3.443

Douglas, H. P., and LeFevre, J.-A. (2018). Exploring the influence of basic cognitive skills on the relation between math performance and math anxiety. J. Num. Cognit. 3, 642-666. doi: 10.5964/jnc.v3i3.113

Dowker, A., Bennett, K., and Smith, L. (2012). Attitudes to mathematics in primary school children. Child Dev. Res. 2012:124939. doi: 10.1155/2012/12493

Dowker, A., Sarkar, A., and Looi, C. Y. (2016). Mathematics anxiety: what have we learned in 60 years? Front. Psychol. 7:508. doi: 10.3389/fpsyg.2016.00508

Dulaney, F., Herts, J. B., Borgonov, F., and Beilock, S. (2017). The math anxietyperformance link: a global phenomenon. Curr. Dir. Psychol. Sci. 26, 52-58. doi: $10.1177 / 0963721416672463$

Eysenck, M. W., and Calvo, M. G. (1992). Anxiety and performance: the processing efficiency theory. Cognit. Emot. 6, 409-434. doi: 10.1080/026999 39208409696

Fennema, E., and Sherman, J. A. (1976). Fennema-Sherman mathematics attitudes scales; instruments designed to measure attitudes towards the learning of mathematics by females and males. J. Res. Math. Educ. 7:324. doi: 10.2307/748467

Ganley, C. M., and Vasilyeva, M. (2014). The role of anxiety and working memory in gender differences in mathematics. J. Educ. Psychol. 106, 105-120. doi: $10.1037 / \mathrm{a} 0034099$

Harari, R. R., Vukovic, R. K., and Bailey, S. P. (2013). Mathematics anxiety in young children: An exploratory study. J. Exp. Educ. 81, 538-555. doi: $10.1080 / 00220973.2012 .727888$

Hembree, R. (1990). The nature, effects, and relief of mathematics anxiety. J. Res. Math. Educ. 21, 33-46. doi: 10.2307/74945

Hitch, G. J. (1978a). Numerical abilities of industrial apprentices. Br. J. Occup. Psychol. 51, 163-176. doi: 10.1016/0010-0285(78)90002-6

Hitch, G. J. (1978b). The role of short-term working memory in arithmetic. Cogn. Psychol. 10, 302-323. doi: 10.1016/0010-0285(78)90002-6

Ma, X., and Kishor, N. (1997). Assessing the relationship between attitude toward mathematics and achievement in mathematics: a meta-analysis. J. Res. Math. Educ. 28, 26-47. doi: 10.2307/749662

Macher, D., Papousek, I., Ruggeri, K., and Paechter, M. (2015). Statistics anxiety and performance: blessings in disguise. Front. Psychol. 6:1116. doi: 10.3389/ fpsyg.2015.01116

Maloney, E. A., Ansari, D., and Fugelsang, J. A. (2011). The effect of mathematics anxiety on the processing of numerical magnitude. Q. J. Exp. Psychol. 64, 10-16. doi: 10.1080/17470218.2010.533278

Maloney, E. A., and Beilock, S. L. (2012). Math anxiety: who has it, why it develops, and how to guard against it. Trends Cogn. Sci. 16, 404-406. doi: 10.1016/j.tics.2012.06.008

Miller, H., and Bichsel, J. (2004). Anxiety, working memory, gender, and math performance. Personal. Individ. Differ. 37, 591-606. doi: 10.1016/j. paid.2003.09.029 
Mononen, M., Niemvirta, M., Koponen, J., Lindskog, M., and Tapola, A. (2021). Developmental relations between mathematics anxiety, symbolic numerical magnitude processing and arithmetic skills from first to second grade. Cognit. Emotion, 1-21. doi: 10.1080/02699931.2021.2015296, [Epub Ahead of Print]

Moustafa, A. A., Al-Emadi, A. A., and Megreya, A. M. (2021). The need to develop an individualized intervention for mathematics anxiety. Front. Psychol. 12:723289. doi: 10.3389/fpsyg.2021.723289

Namkung, J. M., Peng, P., and Lin, X. (2019). The relation between mathematics anxiety and mathematics performance among school-aged students: A metaanalysis. Rev. Educ. Res. 89, 459-496. doi: 10.3102/2F0034654319843494

Núñez-Peña, M. I., and Suárez-Pellicioni, M. (2014). Less precise representation of numerical magnitude in high math-anxious individuals: an ERP study of the size and distance effects. Biol. Psychol. 103, 176-183. doi: 10.1016/j. biopsycho.2014.09.004

Pinxten, M., Marsh, H., De Fraine, B., Vane den Noortgate, W., and Van Danne, J. (2014). Enjoying mathematics or feeling competent in mathematics? Reciprocal effects on mathematics achievement and perceived math effort expenditure. Br. J. Educ. Psychol. 84, 152-174. doi: 10.1111/bjep.12028

Popescu, T., Sader, E., Schaer, M., Thomas, A., Terhune, D. B., Dowker, A., et al. (2019). The brain-structural correlates of mathematical expertise. Cortex 114, 140-150. doi: 10.1016/j.cortex.2018.10.009

Richardson, F., and Suinn, R. (1972). The mathematics anxiety rating scale: psychometric data. J. Counsel. Psychol. 19, 551-554. doi: 10.1037/h0033456

Sarason, I. G. (1977). The Test Anxiety Scale: Concept and Research. Washington DC: Hemisphere, 193-216.

Sarfo, J. O., Garcia-Santillan, A., Adusei, H., Mokhanova, V. S., Drushlvak, M., Semenikhina, O., et al. (2020). Gender differences in mathematics anxiety across cultures: A univariate analysis of variance among samples from twelve countries. Eur. J. Contem. Edu. 106, 105-120. doi: 10.1037/a0034099

Skagerlund, K., Ostergren, R., Vastfjall, D., and Traff, U. (2019). How does mathematics anxiety impair mathematical abilities? Investigating the link between math anxiety, working memory, and number processing. PLos One 14:e0211283. doi: 10.1371/journal.pone.021128

Sorvo, R., Koponen, T., Viholainen, H., Aro, T., Raikkönen, E., Peura, P., et al. (2017). Math anxiety and its relationship with basic arithmetic skills among primary school children. Br. J. Educ. Psychol. 87, 309-327. doi: 10.1111/ bjep. 12151

Spelke, S. E. (2005). Sex differences in intrinsic aptitude for mathematics and science? A critical review. Am. Psychol. 60, 950-958. doi: 10.1037/000366X.60.9.950

SPSS, IBM (2017). IBM Corp. Released 2017. IBM SPSS Statistics for Windows, Version 25.0. Armonk, NY: IBM Corp.

Supekar, K., Iuculano, T., Chen, L., and Menon, V. (2015). Remediation of childhood math anxiety and associated neural circuits through cognitive tutoring. J. Neurosci. 35, 12574-12583. doi: 10.1523/ JNEUROSCI.0786-15.2015

Szczygiel, M. (2020). Gender, general anxiety, math anxiety and math achievement in early school-age children. Issues Edu. Res. 30, 1126-1142.

Szczygieł, M., and Pieronkiewicz, B. (2021). Exploring the nature of math anxiety in young children: intensity, prevalence, reasons. Math. Think. Learn. 1-19. doi: 10.1080/10986065.2021.1882363
Van der Beek, J., Van der Ven, S., Kroesbergen, E., and Leseman, P. (2017). Self-concept mediates the relation between achievement and emotions in mathematics. Br. J. Educ. Psychol. 87, 478-495. doi: 10.1111/ bjep. 12160

Villavicencio, F., and Bernardo, A. (2016). Beyond math anxiety: positive emotions predict mathematics achievement, self-regulation and self-efficacy. Asia Pacific Edu. Res. 25, 415-422. doi: 10.1007/s40299-015-0251-4

Vukovic, R. K., Kieffer, M. J., Bailey, S. P., and Harari, R. R. (2013). Mathematics anxiety in young children: concurrent and longitudinal associations with mathematical performance. Contemp. Educ. Psychol. 38, 1-10. doi: 10.1016/j. cedpsych.2012.09.001

Wang, L. (2020). Mediation relationships among gender, spatial ability, math anxiety, and math achievement. Educ. Psychol. Rev. 32, 1-15. doi: 10.1007/ s10648-019-09487-z

Wang, Z., Lukowski, S., Hart, S., Lyons, I. M., Thompson, L., Kovas, Y., et al. (2015). Is math anxiety always bad for math learning? Psychol. Sci. 26, 1863-1876. doi: 10.1177/0956797615602471

Wang, Z., Shakeshaft, N., Schofield, K., and Malanchini, M. (2018). Anxiety is not enough to drive me away: a latent profile analysis on math anxiety and math motivation. PLoS One 13:e0192072. doi: 10.1371/journal.pone.0192072

Watson, J. (1983). The Aiken attitude to mathematics scales: psychometric data on reliability and discriminant validity. Educ. Psychol. Meas. 43, 1247-1253. doi: $10.1177 / 001316448304300436$

Wechsler, D. (2008). Wechsler Adult Intelligence Scale-Fourth UK Edition. London: Pearson.

Wigfield, A., and Meece, J. L. (1988). Math anxiety in elementary and secondary school students. J. Educ. Psychol. 80, 210-216. doi: 10.1037/0022-0663.80.2.210

Xie, F., Xin, Z. Q., and Zhang, L. (2020). Gender difference of Chinese high school students' math anxiety: The effects of self-esteem, test anxiety and general anxiety. Sex Roles 81, 235-244. doi: 10.1007/s11199-018-0982-9

Zeidner, M., and Matthews, G. (2003). "Test anxiety," in Encyclopedia of Psychological Assessment. ed. R. Fernandez-Ballesteros (London: Sage), 965-969.

Zhang, J., Zhao, N., and Kong, Q. P. (2019). The relationship between math anxiety and math performance: A meta-analytic investigation. Front. Psychol. 10:1613. doi: 10.3389/fpsyg.2019.01613

Conflict of Interest: The authors declare that the research was conducted in the absence of any commercial or financial relationships that could be construed as a potential conflict of interest.

Publisher's Note: All claims expressed in this article are solely those of the authors and do not necessarily represent those of their affiliated organizations, or those of the publisher, the editors and the reviewers. Any product that may be evaluated in this article, or claim that may be made by its manufacturer, is not guaranteed or endorsed by the publisher.

Copyright (c) 2022 Dowker and Sheridan. This is an open-access article distributed under the terms of the Creative Commons Attribution License (CC BY). The use, distribution or reproduction in other forums is permitted, provided the original author(s) and the copyright owner(s) are credited and that the original publication in this journal is cited, in accordance with accepted academic practice. No use, distribution or reproduction is permitted which does not comply with these terms. 